\title{
Communicative Figurations: Towards a New Paradigm for the Media Age?
}

\author{
Giselinde Kuipers
}

\subsection{Introduction: Figurations and Mediations}

In What is Sociology? Norbert Elias introduces the concept 'figuration' with a metaphor: a game of cards. He writes:

When four people are sitting around a table and play cards together, they form a figuration. Their actions are interdependent. Indeed, common $[\ldots]$ usage allows us to speak in this case of "game" as if it had some existence in itself. One can say "the game moves slowly." But despite all objectifying expressions, it is in this case quite clear that the course of the game springs from the interweaving of the actions of a group of interdependent individuals. (Elias 2006[1970]: 172; author's translation).

As Elias discusses these four people and their actions, he gradually unfolds the rationale of the figuration concept. This concept aims to overcome the distinction between 'the individual' and 'the social'. To show how social life is always a process. To show that there are shifting balances of power, rather than fixed positions of power and subordination. Finally, this concept aims to

G. Kuipers $(\square)$

Sociology Department, University of Amsterdam, Amsterdam, Netherlands e-mail: g.m.m.kuipers@uva.nl

(C) The Author(s) 2018

A. Hepp et al. (eds.), Communicative Figurations, Transforming Communications - Studies in Cross-Media Research, https://doi.org/10.1007/978-3-319-65584-0_18 
show that 'the game' - and thus, any social interaction - has a reality and a logic of its own that cannot be reduced to the intentions of individual players.

But can one understand the game by just looking at the players? Elias mentions the role of the table, which should please Latourians. But what about the deck of cards? Without taking into account the cards-are they thrown or held onto, in one person's hand, another's, or on the table, isolated or in specific combinations?-the actions of the human players make little sense. The cards are part of the figuration. Not as actors, however. But what, then?

Reading this volume, it occurred to me that the cards are a medium. The cards relay information between the players, mediating their relations and interactions. They have content (numbers, colours), technology (print) and a material basis (cardboard, plastic coating). They can be recombined to convey different messages. They encompass different genres, ranging from sophisticated (bridge) to simple (old maid), from global (poker) to local (Skat). They even can work on different 'platforms'. Today, many card games are played on the 'meta-medium' (see Hepp and Hasebrink, this volume) of the computer.

All human figurations are mediated. Elias, in the late 1960s, was fighting different battles: against Parsonian functionalism, behaviourism and anti-historicism (Elias 2006 [1970]; Elias and Scotson 2008 [1965]). Thus, he was not concerned with issues of mediation and mediatization. ${ }^{1}$ But in the twenty-first century, increasing mediatization is reshaping social life at a high pace. The role of media in human interaction has taken centre stage. This volume, and the larger research programme into Communicative Figurations that most of its authors are involved in, successfully revives Elias's notion of figuration to make sense of the current age of 'deep mediatization'.

Reading the various chapters, I was struck to see how well the concept of figuration worked to understand the way people organize themselves in fluctuating groups, organized through and around a wide range of media. The figurational approach allows researchers to bridge social life and media life, as well as social theory and media theory. This is an important and timely intervention. Neither social science nor media studies has, in my view, been able to successfully conceptualize the increasing interweaving of media and social life. ${ }^{2}$ The new figurational approach of the 'Bremen School' is an ambitious, potentially fruitful step towards thinking about media and social life as integrated and co-constitutive. 
My reading of this volume was guided by three questions. First, does this figurational approach work? Does it allow us to see things that we previously did not? Do we see relations or patterns that we previously missed? Second, how does the new figurational approach relate to the figurational approach as developed by Elias and his followers? What does it add or improve? Third, is this, or can this be, the beginning of a new paradigm that bridges media and social theory?

\subsection{Does the Figurational Approach Allow Us to See New Things?}

The true test of any theoretical approach is its usefulness: does it allow us to see or understand things that we previously did not? In this volume, the figurational approach is employed to analyze a wide variety of topics: from (non)tweeting clerics to instant-messaging adolescents, and from political decision-making to hacker collectives. Methods vary too: content analysis, surveys, interviews, ethnography. Throughout, the chapters refer to the figurational approach as outlined in the introductory chapter by Hepp and Hasebrink (Chap. 2). This gives the volume coherence and shows the merits of the approach.

All chapters show, in various ways, how people and media come together to create fluctuating figurations. Various forms of media, or 'media ensembles', are central to these figurations. As all authors show, the workings of these figurations cannot be understood without taking into account the diverse media practices of the actors involved. This is as true for adolescent friendship groups as it is for journalists, clerics, social activists or school principals. Moreover, these figurations are not fixed: they change, and they look different from different perspectives. Typically, the authors use the term 'network' (always with the same Elias quote) to describe these shifting figurations. The approach also comes with a clear methodological logic: in most chapters, looking for these networks of actors is the first step of the analysis. The second step is the connection of these networks with their media ensembles. Thus, the analytical steps automatically lead the authors to consider people and media in conjunction.

Many chapters highlight the nested nature of these figurations of people and media. All figurations are embedded in larger 'figurations of figurations'. Thus, organizations and institutions also form networks, 
which operate by the same mediated, fluctuating logic. This nesting is evident in the chapters in the second part, which deal with institutions and organizations such as journalism, blogging, schools and the Church. The nested view is most effective, however, when applied to more fluid domains. The interweaving of different figurations helps us understand bottom-up social action, such as the repair cafés discussed by Kannengießer (Chap. 5) or the hacker collectives discussed by Kubitschko (Chap. 4). Furthermore, the analysis of everyday mediated and unmediated interactions, such as the social life in cities as analyzed by Hepp et al. (Chap. 3), is much enlightened by this layered approach. Finally, this interweaving sheds light on the interconnectedness of global and local, as shown by Robel and Marszolek (Chap. 7).

This nested nature of figurations can also be extended downwards, to everyday interactions or even to individual or intra-individual level: the formation of self and identity, the expression of emotions, the regulation of bodies. The theoretical agenda certainly allows for this. However, the focus seems to be more on the upwards connection, from microtowards meso- and macro-levels, rather than across micro-levels. Every now and then, the chapters offer tantalizing glimpses of an extension towards the shaping of selves and the role of emotions in these figurations. For instance, Wolf and Wudarski discuss the emergence of new, informal ways of learning, and new forms of expertise in online gaming (Chap. 6). Friemel and Bixler show how adolescents bond while communicating through media, about media (Chap. 8). Pritzlaff-Scheele and Nullmeier show that people (sadly) have more trouble reaching decisions in online settings (Chap. 12). In these cases, the figurations expand upwards, towards wider societal networks, but also downwards, towards the shaping of emotions and identities.

Throughout the volume, authors show how people and media come together in figurations through practice. The practice-based approach captures people's simultaneous engagement with various media and other people, highlighting not only the interweaving, but also the coconstitution $^{3}$ of figurations through people and media. The focus on practice means that media and people are seen simultaneously, without one having analytical or causal precedence over the other. In some chapters, the analytical focus on practice is combined with the nesting of figurations on different levels-especially Hepp et al. (Chap. 3); Kubitschko (Chap. 4), Kramp and Loosen (Chap. 9); Breiter and Ruhe (Chap. 13); Friemel and Bixler (Chap. 8). In these cases, the new figurational 
approach to me seemed the most productive theoretically: new connections between media, human action and social groupings became visible that would have been difficult to see with other perspectives.

This volume also shows - maybe inadvertently-how difficult it is to show the interweaving of people and media without looking at practices. Not all methods and topics are equally suited to a practice theory. As is explained in an insightful chapter on methods at the end of the book (Chap. 17), capturing practices is difficult in general. Sometimes, authors in this volume attempt to infer practices from media texts or survey responses. In these cases, the focus on practices becomes somewhat strained, and the simultaneous focus on people and media more tenuous.

Finally, all chapters see figurations are linked by shared 'frames of relevance'. This is a true innovation as compared with the original Eliasian concept. The focus on shared frames of relevance enables researchers to analytically separate figurations. The recurring problem in the study of (informal) networks is that they have no clear boundaries: in the end, everybody is connected to everybody, and everything is connected to everything. Too easily, scholars then fall back on conventional institutional delineations. However, as the chapters in Part II on institutions and organizations show, in this era of deep mediatization organizations often have fuzzy boundaries and many outward connections, while internally they may be fragmented and scattered. The figurational approach allows us to see how 'hard' institutions such as schools, news organizations and even the Church are made up of various communicative figurations, with different linkages to the outside world. Indeed, institutions and organizations in this perspective form the meeting point of many figurations, each held together by shared 'frames of relevance'.

Again, the usefulness of the figurational approach is both theoretical and empirical. The 'frame of relevance' helps to identify and delineate the unit(s) of analysis, and it yields interesting empirical results. Like the focus on practice, not all contributors manage to make optimal use of this concept. Sometimes, authors do not need it because the figuration is rather easy to delineate. More often, the question where figurations end, of how to identify a figuration, is simply not posed. But when applied, as for instance in the contribution of Friemel and Bixler (Chap. 8), Robel and Marszolek (Chap. 7) and Venema and Averbeck-Lietz (Chap. 10), the notion of frame of relevance seems a powerful tool for dealing with the fluidity, unboundedness and interconnectedness of communicative figurations. 
The figurational approach clearly has added value as a theoretical perspective. Throughout the volume, it works as a clear methodological guideline. The chapters consistently connect people with media practices and ensembles. In the majority of the chapters, the figurational approach works well to highlight issues and relations that would otherwise remain unseen. However, in some chapters the figurational approach was more integral to the analysis than in others. The perspective works best when the various elements of the Hepp-Hasebrink three-step programme (constellation of actors, frame of relevance, media practices) are integrated with each other, and inform both theory and empirical approach. A truly fruitful use of this perspective, however, implies the adoption of a number of assumptions that to me appear to underlie the communicative figurations approach. As I see it, these assumptions are: (1) social life is relational; (2) social life is processual; (3) meaning is constitutive of, and emerging from, interaction. I will return to these assumptions at the end of this chapter.

\subsection{Does the New Figurational Approach Improve the Old Figurational Approach?}

The second question that occupied me during the reading of this volume was its relation to the original figurational approach, and 'figurational sociology' as I have come to know it. Reading the volume, I sometimes felt like Darwin on the Galapagos Islands. During a period of separation, two different species have evolved from the same finch. The figurational finch that I am most familiar with was developed by Elias's students and their students, in the Netherlands, Germany and the UK (cf. Mennell 1994; Wouters 2007; Dunning and Hughes 2013). The communicative figurations finch seems to me a uniquely German species, adapted to a habitat of media scholars and German social theorists.

Two innovations of the Bremen finch recur throughout the book: the focus on media and the explicit connection with practice theory. The latter, it seems to me, follows developments in social science as a whole. The specific inspiration in the communicative figurational finch seems to be the work of Nick Couldry (Couldry 2004, 2012). The figurational finch I am more familiar with has evolved in a similar direction, but mostly in interaction with the work of Pierre Bourdieu $(1977,1984)$. Both approaches have been concerned with the relation between figurations of different levels. The figurational sociologists, following the younger 
Elias of The Civilising Process, have focused on the relation between societal change, state formation and 'personality make-up' or 'habitus'. This has led to an engagement with the sociology of emotions and the body on the one hand; and with historical-comparative sociology on the other.

The communicative figurational scholars, maybe influenced by systems theory, have analyzed 'figurations of figurations', mainly focusing on the interactions of systems and organizations within one society. Interestingly, the different approaches have sometimes come up with similar solutions. In this volume, the analysis of 'figurations of figurations' leads Kubitschko to use the metaphor of the spiral (Chap. 4), which is exactly the metaphor chosen by Cas Wouters in his study of informalization (Wouters 2007). In this respect, the two schools seem nicely complementary.

What strikes me most in the communicative figurations finch is its cross-breeding with phenomenology. As noted above, I consider the focus on 'frames of relevance' an important, though not completely developed, theoretical innovation. This concept reflects a deeper engagement with meaning-making as the basis of social life that seems inspired by phenomenology. This comes out clearly in the theoretical companion to this volume, The mediated construction of reality (Couldry and Hepp 2016). The title says it all: Berger and Luckman for the media age.

There are also some characteristics that this finch has lost, or maybe that are still there but atrophied. I have already mentioned the absence of emotions and bodies, and the relative lack of attention to the figurational shaping of selves-all classical themes of the younger Elias of court society and the civilizing process. Most notable is the near-disappearance of Elias's core concept of the power balance. The figuration concept was originally developed in a study of urban inequality and conflict (Elias and Scotson 2008). Power balances are also at the heart of the game metaphor. The players in a game are, as Elias notes, both allies (Verbündete, or people tied together) and adversaries. In the course of the game, power relations shift, but these balances are supported by all players, the weak and the strong. Power is therefore strongly related to Elias's other central concept: interdependencies.

I am inclined to connect the disappearance of power in the Bremen school with the phenomenological slant. Add power to the social construction of reality, and the result easily becomes rather paranoid, or at least deeply Gramscian: the social construction merely a projection of the powerful. However, several of the contributions in this volume could 
have done with the relational power concept as developed in figurational sociology. To name some obvious examples: the relations between people with different levels of expertise in games (Wolf and Wudarski, Chap. 6); the shifting balance of power between journalists and their audiences (Kramp and Loosen, Chap. 9); the power structures limiting the media use of clerics (Radde-Antweiler et al., Chap. 11), and the varying impacts of national states on urban identity (Robel and Marszolek Chap. 7) or media use in schools (Breiter and Ruhe, Chap. 13). Moreover, the relative absence of power in the analysis makes it difficult to grasp the balances of dependence and power between people, media and media producers and organizations. In all case studies in this book, this is an invisible, but all-important figuration: between people and their media, between 'users' and producers'. Interestingly, in these media figurations power balances are often fluid, nested and complex-ideally suited to figurational analysis.

\subsection{Towards a New Paradigm?}

The final question: do we see here the beginning of a new paradigm that bridges social and media theory? As I have argued here, this book presents a novel, potentially very productive approach. The combination of figurational with practice theory is particularly good at simultaneously capturing people and their media, or media and their people. Certainly, from the perspective of social science, this is a great step forward. Despite considerable, I would say fundamental, changes to social life, the toolbox of sociologists has remained fundamentally unchanged since the 1990s (or maybe even since the 1800s). In general, media theory has done better in conceptualizing the two-way relationship between media and persons. Additionally, the communicative figurations approach offers a clear methodological recipe that works well across a range of topics, methodologies and even theoretical traditions.

As I noted above, the communicative figurations approach seems to hinge on three basic assumptions: (1) social life is relational; (2) social life is processual; (3) meaning is constitutive of, and emerging from, interaction. Not all chapters in this book embrace these assumptions, but the editors clearly do. These assumptions link this approach not only to figurational sociology, but to a wider category of theories, many of which are discussed in the theoretical introduction (Chap. 1).

The communicative figurations approach is a member of the family of 'relational theories', which generally is said to include Elias, Bourdieu, 
present-day practice theory, network theory and new institutional theory (cf. Emirbayer 1997; Uitermark et al. 2016). What connects these theories is a focus on relations rather than individuals, and on meaning, value and power as emerging from relations between people. To my knowledge, media in any form are not central to these approaches. The chapters in this book show that media can be included seamlessly in a relational analysis. Here, we have maybe not a new paradigm, but surely the fruitful expansion of an existing paradigm.

The second assumption is the basic processual character of (mediated) social life. Communicative figurations, and the figurations of these figurations, are constantly shifting because of the fluctuating nature of human and human-media relations. The backdrop of every interaction is formed by several longer-term processes, each moving at its own pace. As people are living their mediated lives, they are engulfed by processes of media diversification, growing connectivity and media omnipresence, rapid innovation and datafication (see Hepp and Hasebrink in this volume; Couldry and Hepp 2016). Inherent in the figurational approach, therefore, is the realization that things are always in flux. Moreover, different processes move at different speeds (Elias 2006 [1970]; cf. Abbott 2001). Many authors embraced this processual approach in their framework, but in their analysis reverted to more static approaches. I sympathize with these authors. In fact, the main reason that I am at best a part-time Eliasian is the immense difficulty of being consistently processual in empirical research. However, in an era of fast and deep mediatization, static approaches seem increasingly insufficient. This, then, is a paradigm shift that is difficult, but might be called for. Maybe here, a further integration of media and social theory might help. Media scholars have been developing new tools to study their elusive, fragmented and flighty topic. Other scholars could use their innovation to try anew to capture change.

The third assumption is related to the blending of phenomenological and figurational perspectives in the communicative figurations approach: the centrality of meaning to (mediated) social life. This assumption translates directly into the concept of the 'frames of relevance', which conceptualizes figurations as connections of people through shared meanings and orientations. In other words: what makes a figuration is a sharing of meaning, no matter how fleeting and temporary. This sharing may lead to the construction of new meanings, which can be 'carried' towards yet other figurations. This solves a number of issues related to the original 
concept of figuration. What is the boundary of a figuration? What separates one figuration from another? How do people switch from one figuration to another? Can they be part of several figurations at the same time, and how does this work? These questions were difficult enough to answer before deep mediatization. Today, the ramifications are almost impossible. The concept of a frame of relevance offers us a way to understand the increasingly complex linkages between people, in a way that no paradigm I am aware of can do.

Let us return to the game of cards. The four players share a frame of relevance: the game. However, they may be playing their game in a placesay, a bar-with other people. Presumably, they also share a frame of relevance, though less intensely, with these people. Possibly, their relations with the people in the room vary. Maybe the husband of one of the players is there. Marriage is typically a two-person figuration. The other players may have other shared frames of relevance with this person: family, friend, neighbour. These nested and overlapping figurations can all be captured and analyzed with the concept of the 'frames of relevance', which can be expanded endlessly upward, downward and outward.

Now imagine a game of cards that is played online. Maybe all four players are in different corners of the world. One may be home alone, one in a train, one in a bar, one surreptitiously playing a game at work. In a mediated situation, the permutations are endless. To make up a figuration, physical co-presence is not necessary at all. Especially in such complex mediated cases, thinking of figurations as delineated by shared frames of relevance is a fruitful innovation. The consequence, of course, is that everybody is always part of many figurations at the same time, spread across different locations. But this 'complex and also contradictory' situation, as Hepp, Simon and Sowinska observe (Chap. 3), is the normal state of affairs for most people today.

With this budding new paradigm, we at least have the words to describe it.

\section{Notes}

1. See however, Elias 2010 [1991] and Elias 2011 [1989].

2. As a sociologist, I am sad to admit that media scholars have done a much better job at this than social scientists (see for instance Livingstone 2009; Couldry 2012; van Dijck 2013). Social scientists, when they consider 
media at all, tend to conceptualize them either as a continuation of existing interaction patterns by other means, or as a 'cause' that has 'effects' on individuals and interactions.

3. On co-constitution, (see Breiger 2000; Mohr 2000; Friedland et al. 2014).

\section{REFERENCES}

Abbott, Andrew. 2001. Time matters: On theory and method. Chicago: Chicago University Press.

Breiger, Ronald. 2000. A tool kit for practice theory. Poetics 27 (2-3): 91-115.

Bourdieu, Pierre. 1977. Outline of a theory of practice. Cambridge: Cambridge University Press.

Bourdieu, Pierre. 1984. Distinction: A social critique of the judgment of taste. London: Routledge.

Couldry, Nick. 2004. Theorizing media as practice. Social semiotics 14 (2): 115-132.

Couldry, Nick. 2012. Media, society, world. Social theory and digital media practice. Cambridge: Polity Press.

Couldry, Nick, and Andreas Hepp. 2016. The mediated construction of reality. Cambridge: Polity Press.

Dunning, Eric, and Jason Hughes. 2013. Norbert Elias and modern sociology. Knowledge, interdependence, power, process. London: Bloomsbury.

Elias, Norbert. 2006 [1970]. Was ist Soziologie? Berlin: Suhrkamp Verlag.

Elias, Norbert. 2010 [1991]. The society of individuals. Dublin: University College Dublin Press.

Elias, Norbert. 2011 [1989]. The symbol theory. Dublin: University College Dublin Press.

Elias, Norbert, and John Scotson. 2008 [1965]. The established and the outsiders. Dublin: University College Dublin Press.

Emirbayer, Mustafa. 1997. Manifesto for a relational sociology. American Journal of Sociology 103 (2): 281-317.

Friedland, Roger, John Mohr, Henk Roose, and Paolo Gardinali. 2014. The institutional logics of love: measuring intimate life. Theory and society 43 : 333-370.

Livingstone, Sonia M. 2009. On the mediation of everything. Journal of Communication 59 (1): 1-18.

Mennell, Stephen. 1994. The formation of we-images: A process theory. In Social theory and the politics of identity, ed. Craig Calhoun, 174-197. Cambridge: Blackwell.

Mohr, John. 2000. Introduction: Structures, institutions and cultural analysis. Poetics 27 (2-3): 57-68. 
Uitermark, Justus, Vincent A. Traag, and Jeroen Bruggeman. 2016. Dissecting discursive contention: A relational analysis of the Dutch debate on minority integration, 1990-2006. Social Networks 47: 107-115.

van Dijck, José. 2013. The culture of connectivity. A critical history of social media. Oxford: Oxford University Press.

Wouters, Cas. 2007. Informalization: Manners and emotions since 1890. London: Sage.

Open Access This chapter is licensed under the terms of the Creative Commons Attribution 4.0 International License (http://creativecommons.org/licenses/ by $/ 4.0 /$ ), which permits use, sharing, adaptation, distribution and reproduction in any medium or format, as long as you give appropriate credit to the original author(s) and the source, provide a link to the Creative Commons license and indicate if changes were made.

The images or other third party material in this chapter are included in the chapter's Creative Commons license, unless indicated otherwise in a credit line to the material. If material is not included in the chapter's Creative Commons license and your intended use is not permitted by statutory regulation or exceeds the permitted use, you will need to obtain permission directly from the copyright holder.

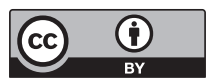

